\title{
Cardiac Stress Test
}

National Cancer Institute

\section{Source}

National Cancer Institute. Cardiac Stress Test. NCI Thesaurus. Code C100073.

The use of physical activity to elicit signs and symptoms of myocardial ischemia. (ACC) 